\title{
A Network Pharmacology-Based Strategy for Predicting Active Ingredients and Potential Targets of LiuWei DiHuang Pill in Treating Type 2 Diabetes Mellitus [Corrigendum]
}

\author{
He D, Huang JH, Zhang ZY, et al. Drug Des Devel Ther.
}

2019;13:3989-4005.

The authors missed to mention equal contribution of the authors Dan He and Jian Hua Huang in the author list. The revised author list should appear as follows:

\author{
Dan $\mathrm{He}^{\mathrm{l}, *}$ \\ Jian-Hua Huang ${ }^{1-3, *}$ \\ Zhe-Yu Zhang ${ }^{4}$ \\ Qing $D u^{\prime}$ \\ Wei-Jun Peng ${ }^{4}$ \\ Rong $\mathrm{Yu}^{1,2}$ \\ Si-Fang Zhang ${ }^{4}$ \\ Shui-Han Zhang' \\ Yu-Hui Qin'
}

'Hunan Academy of Chinese Medicine, Hunan University of Chinese Medicine, Changsha, Hunan 410013, People's Republic of China; ${ }^{2}$ Hunan Key Laboratory of TCM Prescription and Syndromes Translational Medicine, Changsha, Hunan 410208, People's Republic of China; ${ }^{3} 201$ I

Collaboration and Innovation Center for Digital Chinese Medicine in Hunan, Changsha 410013, People's Republic of China; ${ }^{4}$ Department of

Gastroenterology, Xiangya Hospital, Central South University,

Changsha, Hunan 410008, People's Republic of China

*These authors contributed equally to this work

\section{Publish your work in this journal}

Drug Design, Development and Therapy is an international, peerreviewed open-access journal that spans the spectrum of drug design and development through to clinical applications. Clinical outcomes, patient safety, and programs for the development and effective, safe, and sustained use of medicines are a feature of the journal, which has also

been accepted for indexing on PubMed Central. The manuscript management system is completely online and includes a very quick and fair peer-review system, which is all easy to use. Visit http://www. dovepress.com/testimonials.php to read real quotes from published authors. 